\title{
The Measurement of Economic, Social and Environmental Performance of Countries: A Novel Approach
}

\author{
Maria Francesca Cracolici · Miranda Cuffaro $\cdot$ Peter Nijkamp
}

Accepted: 9 March 2009/Published online: 9 April 2009

(C) The Author(s) 2009. This article is published with open access at Springerlink.com

\begin{abstract}
This paper presents a new analytical framework for assessing spatial disparities among countries. It takes for granted that the analysis of a country's performance cannot be limited solely to either economic or social factors. The aim of the paper is to combine relevant economic and 'non-economic' (mainly social) aspects of a country's performance in an integrated logical framework. Based on this idea, a structural simultaneous equation model will be presented and estimated in order to explore the direction of the causal relationship between economic and non-economic aspects of a country's performance. Furthermore, an exploration of the trajectory that each country has registered over time along a virtuous path will be offered. By means of a matrix persistency/transition analysis, the countries will be classified in clusters of good/bad performance. One of the most interesting conclusions concerns the inability of most countries to turn the higher educational skills of the population into greater economic performance over time. In addition, our analysis also shows that making an accurate picture record and formulating related policy aiming at environmental care is highly desirable. It is surprising that only a few countries have reached a favourable economic and environmental performance simultaneously.
\end{abstract}

Keywords Socio-economic well-being · Living standards ·

Structural simultaneous equation model

M. F. Cracolici ( $\square)$ · P. Nijkamp

Department of Spatial Economics, Free University, Amsterdam, The Netherlands

e-mail: mcracolici@feweb.vu.nl

P. Nijkamp

e-mail: pnijkamp@feweb.vu.nl

M. Cuffaro

Department of National Accounting and Analysis of Social Processes, University of Palermo, Palermo, Italy

e-mail: cuffaro@unipa.it 


\section{Introduction}

The measurement of a country's welfare is one of the most critical and highly debated issues in economic research. The snappy title of Davidson's book highlights one of the most relevant and debated topics of the recent literature: "You can't eat GNP" (Davidson 2000). This publication addresses the hypothesis that GNP (or GDP) per capita cannot be considered as the only indicator of the performance of a country because it does not capture the overall well-being of population.

Nevertheless, it has become rather common to rank the performance of countries or regions by assessing their levels of development (or growth) in terms of GDP. But this approach has often been strongly criticized. As the World Bank has written: "The basic objective of development is to create an enabling environment for people to enjoy long, healthy and creative lives. But it is often forgotten in the immediate concern with the accumulation of commodities and financial wealth" (World Bank 2001, p. 9).

The conventional economic view has frequently prompted much criticism based on the observation that "people derive utility or well-being not merely from the command over income alone" (Neumayer 2003, p. 276). This observation takes for granted that the standard GDP index is unable to capture the real inequalities among countries in terms of the different-sometimes contrasting-dimensions of the well-being of populations. GDP is at best only a partial measure (or proxy) of a multi-dimensional welfare concept incorporating both the economic and the non-economic aspects of human life (see Sen 1985, 1987; Khan 1991; Dasgupta 1990).

Since the 1990s however, there have been some new attempts in the literature to come up with more appropriate indicators. The first is the World Bank's human development index (HDI), a composite indicator based on GDP per capita, life expectancy at birth, and the adult literacy rate (UNDP 1990). These features represent, respectively, three main aspects of an individual's life, viz. access to resources; health conditions; and the opportunity to enjoy a basic education.

Although the HDI is the most frequently used indicator for measuring the development differentials among countries, it has been much criticized, in particular regarding its simple weighting of each variable, and the high correlation between GDP and certain crucial background variables.

In 2005 a special issue of the Review of Income and Wealth was entirely dedicated to 'Inequality and Multidimensional Well-being', while in 2007 one of its calls for papers was mainly addressed to specific related themes, such as: measuring well-being from objective and subjective perspectives, constructing macro indicators of well-being, measuring economic well-being among regions, and so forth.

In 2001 an original and stimulating study (Hobijn and Franses 2001) drew economists' attention to the need to extend the evaluation of a country's performance to encompass relevant measures of living standards. In so doing, they have thus readdressed the spatial convergence issue-so prominent in the economic growth literature-and presented evidence that convergence in GDP does not necessarily imply convergence in living standards, the latter being defined by daily calorie supply, protein calorie supply, infant mortality, life expectancy at birth, and so forth.

In our view, and in agreement with the above-mentioned literature about the need to follow a multidimensional approach to the analysis of national or regional well-being, the assessment of a country's performance cannot be limited solely to either the economic or the non-economic aspects. Both aspects must be considered simultaneously, and within a consistent framework. 
More specifically, the level of GDP in a country is viewed as its ability to provide its inhabitants with proper opportunities to enjoy good economic, social, and environmental conditions of life. An increase in per capita GDP is considered as a basic prerequisite for improvement in the living standards of a population, viz. better health services, more secure livelihoods, greater access to education, better working conditions, security against crime, more satisfying leisure time, a healthy and sustainable environment, etc. On the other hand, better living standards constitute a good basis to enhance productivity and, in turn, GDP.

In the light of these considerations, in the remainder of this paper we shall propose a simultaneous equation system to take into account various relevant aspects, economic and non-economic, related to the living conditions of the population. In the literature, these aspects are often also called, respectively, economic and non-economic well-being (see, e.g. Osberg and Sharpe 2005; McGillivary 2005; McGillivary and Shorrocks 2005). The main idea is to identify a cycle where an increasing amount of GDP per capita (i.e. the economic dimension of a country's performance) produces a higher level of non-economic aspects, viz. better health conditions, longer life prospects, higher percentage of educated population, balance between work and free time, etc. Similarly, if a country has a high level of non-economic well-being factors it is more able to manage its resources in order to increase its income and productivity. Consequently, it seems plausible to hypothesize that there exists a bidirectional relationship between the economic and non-economic dimensions of country performance, and this question will be further analysed in the present paper.

Using a simultaneous equation model (SEM), we explore whether there is a bidirectional causal relationship between the economic and the non-economic aspects that characterize country performance, and how strong the intensity of this mutual causality is.

To this end, we have designed a SEM, where each relevant dimension of well-being is represented by an explanatory equation, and where each equation contains both endogenous and exogenous variables. By means of our SEM, we can control the possible endogeneity problem between economic and non-economic variables. The model is based partly on both the conventional production function theory and partly on the most recent empirical literature on economic growth. Using an extensive database, the model is estimated for 64 countries for the period 1980-1999; the sample involves mainly developing countries, but it has also been implemented for a few developed countries.

After a brief literature review presented in Sect. 2, a first attempt to build an operational framework for the analysis of country performance is provided in Sect. 3; our empirical model and the data used are also presented there. Empirical results and some concluding remarks are presented in Sects. 4 and 5, respectively.

\section{The Multifaceted Performance of a Country}

The economic analysis of regional growth and its distribution already has a long history and dates back to the early work of Solow (1956), where he argues that, in a neoclassical economic world, the growth rate of a region (measured in per capita income) is inversely related to its initial per capita income, a thesis which offers an optimistic perspective for poor regions. This convergence idea has attracted much attention and has prompted interesting qualitative research on evolving convergence versus persistent disparities (see, e.g. Barro and Sala-i-Martin 1992). 
This stream of research has dominated the economic analysis of a country's welfare, though recently a new approach involving also non-economic aspects of a country's wellbeing is emerging. Concerning the latter, some economists consider GDP per capita as a very limited measure of the level of a country's well-being, because it does not consider the consequences of economic development on the lives of people (e.g. air, sea and water pollution, increases in certain rare diseases, congestion, cost of urbanization, etc.); nor does it capture the real-life conditions of populations (UNDP 1990; Hobijn and Franses 2001; Neumayer 2003; Marchante and Ortega 2006).

In 1973, Kuznets made this challenging assertion: "The most distinctive feature of modern economic growth is the combination of a high rate of aggregate growth with disrupting effects and new problems" (Kuznets 1973, p. 257). This statement implies that the national accounting framework should be expanded so that it considers both certain costs (i.e. pollution, urban concentration, commuting, etc.) and positive returns (i.e. better health, greater longevity, more leisure, less income inequality, etc.).

In the light of these suggestions, the economic literature has proposed different measures of a country's performance. The one most widely used is the HDI based on a concept of human development which involves both an economic dimension, measured by GDP per capita, and a dimension linked mainly to social aspects, measured by life expectancy and the literacy rate. It has been inspired by Sen's development theory, according to which a country's development is a matter not only of long-run economic growth but also of opportunities for people, in both the high and the low growth cycle (Sen 1984).

Yet, after the first report on HDI (UNDP 1990), many criticisms were made of the index. Indeed, it has sometimes even been considered a redundant indicator that provides little additional information on inter-country development levels with respect to traditional GDP (McGillivary 1991; Desai 1991; Dasgupta and Weale 1992; Sagar and Najam 1998). Nevertheless, the framework for calculating the index has remained substantially unchanged in UNDP's subsequent annual reports; only few corrections have been made to take account of gender differentials or income distribution.

The specific literature of the 1990s comprised a number of critical proposals for the improvement of the HDI. For example, since the indicators of the three dimensions of HDI were closely correlated, a principal component method was proposed in order to use a linear combination of these indicators (Noorbakhsh 1998; McGillivary 1991).

Further, Sagar and Najam (1998) proposed a more in-depth revision of HDI involving multiplication of the three component variables instead of using their arithmetic average, a logarithmic treatment of GDP, and the incorporation of an inequality measure into the index. In fact, only the second Report calculated the distribution-adjusted HDI for 53 countries (UNDP 1991, pp. 17-18), and this was available until 1994, although since that year the distribution-adjusted HDI has been omitted.

Notwithstanding its limitations, the HDI is particularly relevant to developing countries, where the basic dimensions depicted by the three indicators have not yet been fully accomplished. By contrast, regarding the developed countries, a decent standard of living, longevity, and primary education have already been achieved by most people. Consequently, multiple significant and suitable indicators, which take account of the different aspects of living appear to be necessary.

Recently, in fact, Marchante and Ortega (2006), in a study conducted to measure the quality of life and economic convergence across Spanish regions, have used an alternative augmented composite indicator (AHDI) in the context of HDI. In particular, they considered alternatively three different per capita income measures (total personal income minus grants, GVA, and total disposable income) and six quality of life indicators (life 
expectancy at birth, the infant survival rate, the probability at birth of surviving to the age of 60 , the adult literacy rate, the mean years of schooling of the working age population, and the long-term unemployment rate). Moreover, they applied an averaged arithmetic mean scheme with (arbitrary) weights for the variables transformed by an achievement index.

Cuffaro et al. (2008) analysed the performance of Italian regions by using both different categories of consumption expenditure as proxies of the economic aspects of well-being, and indicators of health and diet conditions, education, labour market, etc. as proxies for the social aspects of well-being. Their analysis showed that it was possible for high levels of economic well-being to coexist with a high level of non-economic well-being.

Furthermore, since the 1980s - after the creation of the United Nations World Commission on Environment and Development-some economists have highlighted that the environment, like the social aspects of life, is an essential element of well-being or country performance. In 1989, Daly and Cobb proposed the so-called ISEW, viz. the first index of sustainable economic welfare; it attempted to integrate the economic aspects of an economy, as depicted by the conventional national accounting, with social (i.e. income distribution inequality) and environmental (i.e. air and water pollution) aspects.

ISEW was criticized very soon (see, e.g. Neumayer 1999, 2000) for the arbitrary selection of its component variables and for the method of aggregation and construction. After that, various indices, such as the living planet index, the ecological footprint, the environmental performance index and so forth, were proposed (see, e.g. Bohringer and Jochem 2007).

At present, there is a big debate among ecological economists concerning the appropriate way to define a multidimensional index of sustainability, combining the economic, social and environmental aspects of human life (Pulselli et al. 2006; Distaso 2007). Actually, the assessment of the environmental aspects is very important in developed countries where growth and technological progress may become 'uneconomic', through worsening the life of citizens by, for example, air and water pollution. Even in developing countries the policies towards environmental problems constitutes a plus point for those governments. Moreover, considering this feature in a multidimensional measure of country performance could produce a more significant ranking of territorial areas.

Although a number of efforts have been made to obtain a more comprehensive index of multidimensional well-being or country performance, many methodological issues still need to be explored more deeply, concerning how to integrate the above-mentioned different aspects in a unique measure (i.e. a composite indicator).

The above considerations indicate that many dimensions should be considered for the analysis of a country's performance. So, how are these dimensions linked? To this end, an operational framework including economic and non-economic (social and environmental) aspects of country performance will now be presented in Sect. 3. It is a first attempt to provide a conceptual and structural framework for the analysis of disparities in a country's performance. The empirical model and its statistical results will also be presented.

\section{A Conceptual Scheme for the Analysis of a Country's Performance}

\subsection{Introductory Remarks}

In our view, an endeavour to combine the economic and the social aspects of a country's performance and to link static and dynamic analysis requires a general framework like the 


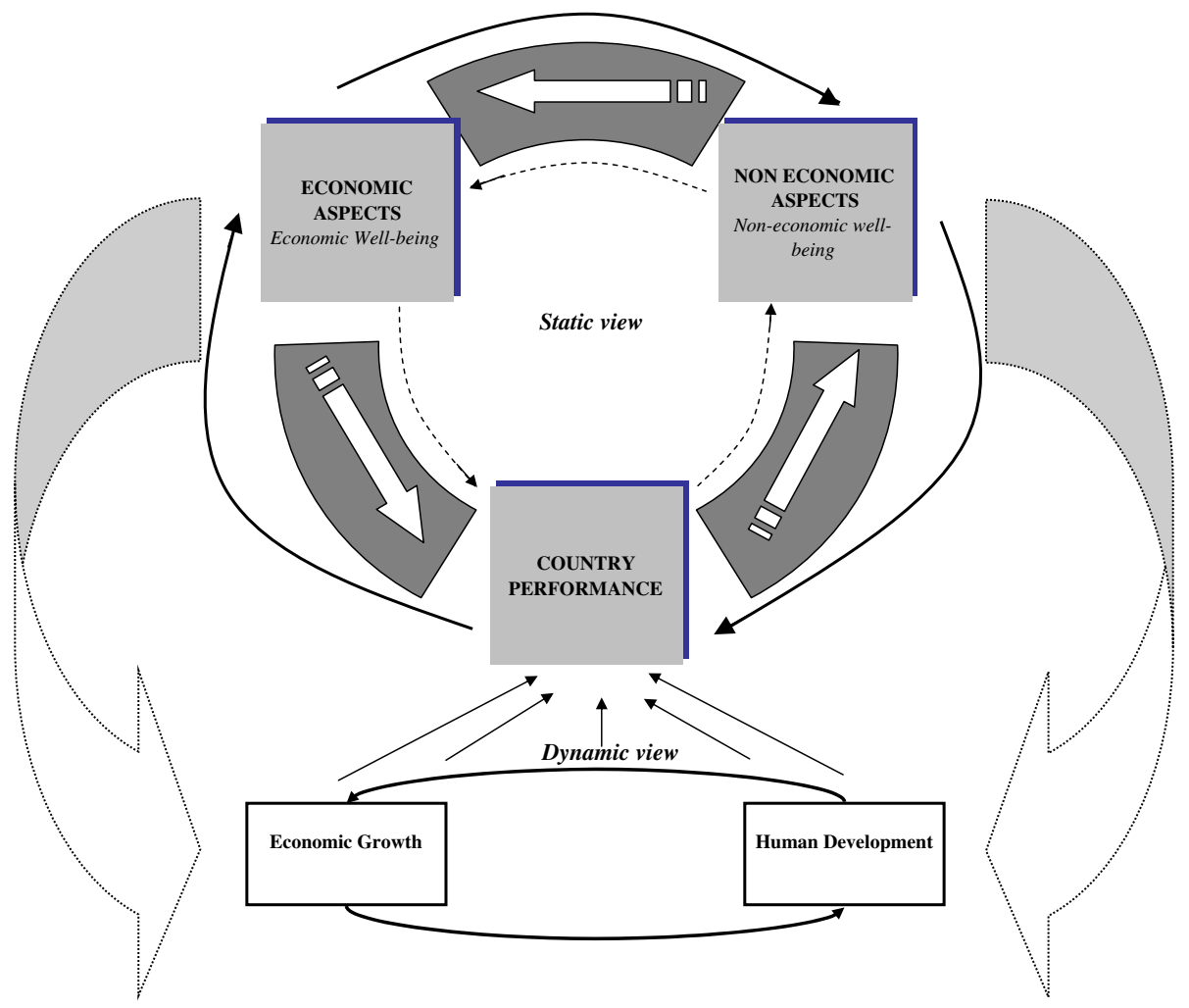

Fig. 1 Operational scheme for the assessment of economic and non-economic performance of countries

one depicted in Fig. 1. This has been inspired by Sen's development theory, according to which a country's development is a matter not only of long-run economic growth but also of opportunities for people, in both the high and the low growth cycle (Sen 1984).

In this scheme, both the economic and the non-economic aspects of a country contribute to its performance. By introducing the time dimension, we can refer to income growth (i.e. the improvement in living conditions) and to human development (i.e. the improvement in non-economic aspects of living).

As a rule of thumb, we expect a strong relationship between both economic and noneconomic aspects, between income growth and human development. As far as we know, there are no empirical studies about the first relation, and there are only few studies about the second one. While some economists (Zuvekas 1979) have found that economic growth and human development are unrelated, some others have found strong support for the opposite hypothesis.

Mazumdar (2000) found evidence that in the middle- and low-income countries there is one-way causal relationship between the two phenomena, ${ }^{1}$ but only up to a certain level of income, after which growth and human development move independently. The results, as highlighted by the author, vary with respect to both the three different indicators of human

\footnotetext{
1 The test is performed on the basis of three single linear equations between GDP per capita (as a standard measure of economic growth) and, respectively, life expectancy at birth, infant survival rate, and adult literacy rate; the latter three variables are proxies for human development.
} 
development and the different income level clusters. In particular, for the low and middleincome countries human development precedes economic growth, that is, low social development implies low labour productivity and in turn low income.

Moreover, Ranis et al. (2000) demonstrated an 'iterative process' between the improvement in human development and economic growth "as a necessary but not sufficient condition for achieving such improvements". They conclude that "economic growth itself will not be sustained unless preceded or accompanied by improvements in human development" (p. 213).

In agreement with the previous empirical evidence, we define an operational scheme based on the argumentation that, in the long run, the causal relationship between the economic and the non-economic aspects may reveal two paths: high levels of economic well-being contribute to high levels of non-economic well-being through households, firms and the public sector. It does so through households because they spend a higher proportion of their income on education, health and culture; through firms because they devote a higher proportion of their profits to create a safer labour environment, to finance R\&D to control pollution, etc.; and through the government because it allocates a higher proportion of its resources to education, health, and the environment. Conversely, high levels of noneconomic well-being contribute to high levels of economic well-being through various channels. For example, high levels of health and education raise the productivity of workers, facilitate the acquisition of skills, and promote technological progress and ICT usage. In their turn, these factors help to significantly increase the level of output (and also its composition), exports, and per capita disposable income.

More specifically, a high level of economic well-being should support the formation of a high level of such human capabilities as improved health or knowledge. Improving human capabilities means increasing the efficiency of the use made by people of their own capabilities for work or leisure (UNDP 1997). In synthesis, the performance of a country is defined by a cycle, viz. a bidirectional path that moves both from the economic dimensions to the non-economic ones and from the non-economic dimensions to the economic ones.

So, how should we measure the economic and the non-economic aspects of a country's performance?

\subsection{Economic and Non-Economic Aspects of a Country's Performance}

In our analysis, the economic dimension of country performance, viz. the access to economic resources - as argued by UNDP (1997) — is evaluated by the traditional GDP per capita. We hypothesize that the ability of a country to satisfy the basic needs of population comes from the opportunities and the efficiency to manage its human, material, and natural capital. From a theoretical point of view, the latter are inputs of the GDP production process.

In the long run, the capacity of the economy to grow fast pushes up the non-economic aspects of a country. Regarding these, very little attention has been paid to which particular indicators have to be chosen. Indeed, this is not immediately obvious at the outset, because the decision also depends on the main features of the countries analysed: for instance, whether they are developed or developing.

Many studies do not devote much attention to this problem. For example, the indicators chosen by Hobijn and Franses (2001)—who analyse both developed and developing countries simultaneously - can well discriminate between the two groups of countries, but they fail to take account of different levels of well-being within developed countries. In fact, when measured on these indicators (viz. daily protein, calorie supply, infant mortality 
rate, and life expectancy at birth) developed countries are quite homogeneous. Later, Neumayer (2003) criticized the previous authors and tested (on the same data set used by Hobijn and Franses) for convergence with different indicators of well-being, namely life expectancy, infant survival, education enrolment, literacy, and telephone and television availability. The wider range of indicators considered offsets the bias due to the analysis of developed and developing countries simultaneously. As a matter of fact, Neumayer reached different results compared with those of Hobijn and Franses that suggest strong evidence of convergence for most of the indicators.

More recently, Giles and Feng (2005), analysing 14 OECD countries, considered five measures of well-being: namely, life expectancy, the Gini index of income inequality, the poverty rate, the tertiary education participation rate, and carbon dioxide $\left(\mathrm{CO}_{2}\right)$ emissions.

Also, McGillivary (2005) for a selected number of developing countries examines a number of indicators, including measures of poverty, inequality, health status, education status, gender bias, empowerment, governance, and subjective well-being. He found that most of the commonly used indicators are highly correlated to income and, as a consequence, they are not able to give any more information than income can. Moreover, he raises the problem of the possible endogeneity between income and non-economic indicators.

In the light of the aforementioned literature, we think that the choice of indicators should be based on the main characteristics of countries (viz. developed or developing; low, medium or high income, etc.), and on their capacity to catch the relative heterogeneity among countries, but avoiding possible redundant statistical information. Obviously, in order to perform significant comparisons between countries, there would have to be wide agreement on the chosen indicators.

In particular, as our analysis concerns a relevant share of developing countries, we think that, in line with the literature, the main dimensions of non-economic well-being should be related to long life prospects (i.e. life expectancy at birth), health (i.e. infant survival rate as the inverse of infant mortality rate), and education (i.e. literacy rate) status.

In relation to the first indicator, as Ram and Schultz (1979, p. 402) pointed out "the satisfaction (utility) that people derive from a longer life span must be substantial"; linked to this one, there is the infant survival rate, which, if it is very high, tends to raise the life expectancy. Finally, the literacy rate is "a direct measure of achievement, one basic sign of human beings' minimum education" (Mazumdar 2000, p. 301).

In addition to these dimensions, it is increasingly recognized that the quality of the environment is worth considering when measuring country performance. As ecological economics points out: "The economic system is a subsystem of the system which is the environment. The economy depends upon the environment, what happens in the economy affects the environment, and changes in the environment affect the economy. Regarded as two systems, the economy and the environment are interdependent" (Common and Stagl 2005, p. 87).

The well-known Kuznets curve (EKC) predicts pollution increases until a certain level of income (viz. \$5,000-\$8,000), as developing countries "grow first and clean up later". A recent paper (Dasgupta et al. 2006) demonstrates that this argument is incorrect and finds evidence that an environmental governance is also possible for developing countries. More specifically, their results suggest that policy actions are sufficient to reduce air pollution significantly, even in those cities of overcrowded and poor countries. This is an important result that makes it possible to take the environment into account when assessing developing countries' well-being. 
An empirical model of country performance, addressing both economic and non-economic aspects, will be proposed in Sect. 3.2. By using a SEM, we aim to verify if a bidirectional relationship exists between the economic and the non-economic dimensions for 64 countries in the world for the years 1980-1999.

\subsection{Model and Data}

To define the model and to choose the key variables to be included, the lessons from the most relevant literature quoted above have been followed. In particular, by means of a SEM, an empirical application of the operational scheme has been performed. By using this SEM, we attempt to arrange and to combine in a synthetic and structural way the various ideas from the literature, in order to capture the effects of the relationship between economic and non-economic aspects that charactize country performance, viz. the simultaneous relationships between the economic and the non-economic aspects of country well-being (see Fig. 1). As far as we know, this approach is the first attempt to arrange the different dimensions of country performance, controlling for endogeneity.

The endogenous variables in our SEM are gross domestic product $(g d p)$, literacy rate (li), life expectancy (le), and pollution indicator ( $p o l)$.

We use as exogenous variables the following: working age population at $\mathrm{t}-1$ as a proxy for labour input (labour); the share of gross capital formation at t-1 (capform) in GDP, as a proxy for material capital input; telephone mainlines (telp) as a proxy for technology progress; television set availability (tels) as a proxy for information diffusion, which indirectly affects $g d p$, and directly the literacy rate (li) and life expectancy (le); educational enrolment to primary, secondary and tertiary school $(e e)$ as a determinant of the literacy rate and indirectly of $g d p$; the urbanization rate $(u r b)$, as a determinant of pollution in terms of emission of $\mathrm{CO}_{2}$.

We assume that the exogenous variables are determining the endogenous variables by the following equations system.

$$
\begin{aligned}
& g d p_{i t}=\alpha_{1}+\beta_{11} \text { labour }_{i t-1}+\beta_{12} \text { capform }_{i t-1}+\beta_{13} \text { telp }_{i t}+\beta_{14} l e_{i t}+\beta_{15} l i_{i t}+\varepsilon_{1 i t} \\
& l i_{i t}=\alpha_{2}+\beta_{21} g d p_{i t}+\beta_{22} e e_{i t}+\beta_{23} t_{e l} s_{i t}+\varepsilon_{2 i t} \\
& l e_{i t}=\alpha_{3}+\beta_{31} l i_{i t}+\beta_{32} t e l s_{i t}+\beta_{33} g d p_{i t}+\varepsilon_{3 i t} \\
& \operatorname{pol}_{i t}=\alpha_{4}+\beta_{41} g d p_{i t}+\beta_{42} u r b_{i t}+\beta_{43} \text { tels }_{i t}+\varepsilon_{4 i t}
\end{aligned}
$$

Clearly, the explanatory structure of the above SEM is co-determined by data availability. The first equation-according to production theory-captures the variables that are likely to influence the GDP production process, i.e. the exogenous variables previously described and the endogenous ones $l e$ and $l i$ that affect the productivity and, consequently, the rise of income. ${ }^{2}$ The $g d p$ as an economic dimension directly affects the country performance, but also indirectly, through its effect on the explanation of other endogenous variables.

The next two Eqs. 2 and 3 describe the non-economic dimensions of country performance, viz. social features, ${ }^{3}$ while Eq. 4 aims to describe the environmental dimension. In Eq. 2, the literacy rate $(l i)$ is explained by gross domestic product $(g d p)$, education

\footnotetext{
${ }^{2}$ Because of the existence of correlation problems between labour and capform and the other exogenous variables, time lags have been used.

${ }^{3}$ Social factors incorporate many dimensions, including security, respect for human rights, etc. but in our framework we are restricting ourselves to measurable factors.
} 
enrolment to primary, secondary and tertiary school (ee), and television set availability (tels). Eq. $3^{4}$ links life expectancy to gross domestic product ( $g d p$ ), education level $(l i)$ and information level; it is plausible to hypothesize that increasing the level of $g d p, l i$ and $t e l s$ increases the prospects for longer life and better health conditions, so that it might positively affect life expectancy.

The last equation links pollution ( $p o l$ ) measured by the emission of $\mathrm{CO}_{2}$ to the production of GDP and to the level of urbanization (urb). It should be noted that the production of $g d p$ cannot be expanded infinitely without some negative external effects on the environmental equilibrium of a country. So one can discriminate between 'good or desirable output' and 'bad or undesirable output' (i.e. pollution); the notion that desirable and undesirable outputs are jointly produced is called 'null jointness' (Shephard and Färe 1974). Bad outputs could be considered in a production function, as in Färe et al. (1994) or in Cracolici et al. (2009); conversely, as in Welsch (2007), it could be inserted in the production function as a quasi-input. ${ }^{5}$ On the other hand, this quasi-input is strictly correlated with the level of output, the urbanization or concentration of activities, the number of motor vehicles and electricity production from oil, etc.

The SEM composed of Eqs. 1-4 constitutes a schematic, but clearly non-exhaustive, efficacious representation of the multifaceted nature of a country's performance.

Because of heteroskedasticity problems, all the variables have been transformed into logs; this allows us to interpret the results in terms of elasticities. We have next used in our econometric analysis a 2-stage least squares (2SLS) estimation method based on instrumental variables (IV) for panel data (Hsiao 2003), i.e. an equation-by-equation robust estimation approach. The 2SLS IV estimation method allows us to obtain consistent results, while it also has the advantage over a system estimation (e.g. a 3SLS estimation method) in that if one equation is misspecified it will not spill over and contaminate the estimation results for the other equations. Moreover, the 2SLS IV method lets us use different and suitable instruments for each equation.

To implement the model we use data from World Bank (2001). In particular, the analysis concerns the year from 1980 to 1999. As not all countries and not all variables have data availability over the period analysed, we made an appropriate choice of either countries or variables. Hence, we use observations at 5-year intervals, around 1980, 1985, 1990, 1995 and 1999. In most cases, these are an average of five annual observations centred on the year indicated. Section 4 contains a discussion of the results obtained.

\section{Empirical Results}

The empirical results that originated from the SEM are reported in Table 1. Regarding the economic dimension, the estimates of Eq. 1 highlight that $g d p$ is positively linked to life expectancy (le), the share of working age population (labour), and the proxy for capital stock (capform), and the proxy for technological progress (telp). As expected, the elasticity of output $(g d p)$ with respect to labour is higher than it is to the stock of capital (capform).

\footnotetext{
${ }^{4}$ It should be noted that Eqs. 1 and 3 included, as a first step, the endogenous variable infant survival (is); but, after a diagnostic statistical analysis it has been removed because of the strong correlation between $i s$, labour, and telp.

5 It should be noted that, as a first step, pol was been inserted in Eq. 1 as quasi-input; but it caused strong bias in the estimates and, consequently, it has been removed.
} 
Table 1 Estimates from the 2SLS IV simultaneous model

\begin{tabular}{lcccc}
\hline Variables & $G d p$ & $L i$ & $l e$ & $p o l$ \\
\hline labour & $0.695(0.043)$ & - & - & - \\
capform & $0.128(0.008)$ & - & - & - \\
telp & $0.124(0.000)$ & - & - & - \\
$l i$ & $0.030(0.663)$ & - & $0.015(0.383)$ & - \\
le & $0.472(0.067)$ & - & - & - \\
gdp & - & $0.679(0.000)$ & $0.114(0.000)$ & $0.890(0.000)$ \\
ee & - & $0.185(0.001)$ & - & - \\
tels & - & $0.064(0.000)$ & $0.006(0.021)$ & $-0.043(0.002)$ \\
urb & - & - & - & $0.402(0.003)$ \\
Constant & $1.725(0.029)$ & $-4.300(0.000)$ & $3.245(0.000)$ & $-7.704(0.000)$ \\
$R^{2}$ & 0.812 & 0.521 & 0.665 & 0.769 \\
\hline
\end{tabular}

Furthermore, it should be noted that the sum of the main input coefficients of the production process - including telp as proxy for technological progress-is almost equal to 1 highlighting constant returns of scale. Among the endogenous variables, the coefficient of the literacy rate is not significant, a phenomenon that could be related to the features of the majority of countries included in the sample, which presents a low level of human capital quality, i.e. a level of the literacy rate not sufficient enough to affect the production of GDP.

Instead, the $g d p$ significantly affects the literacy rate of a country, as shown by the coefficient equal to 0.679 . Thus, there exists only a unidirectional relationship from $g d p$ to $l i$, i.e. $g d p$ precedes $l i$. Life expectancy (le) has a strong and significant effect on $g d p$, it has a coefficient equal to 0.472 ; on the other hand, $g d p$ also has a positive and significant effect on life expectancy $\left(\beta_{33}=0.114\right)$. In synthesis, the estimates from Eqs. 1 and 3 show a bidirectional relationship between $g d p$ and $l e$.

If we now turn to the literacy rate, we find, as expected, that the estimates show a positive sign for all the estimated coefficients. In particular, $l i$ is affected by education enrolment (ee), and by the proxy for information diffusion (tels); these variables represent significant coefficients equal to 0.185 and 0.064 , respectively. The high value of the constant coefficient indicates that some other variables could influence the explanation of $l i$.

Regarding Eq. 3, the estimates highlight that $l e$ is mainly explained by $g d p$, and weakly by tels. In contrast to our poor expectation, the coefficient of the literacy rate is not significant. In the light of this finding, we can say that the non-economic dimensions are strongly explained by income per capita, but, as said above, the inverse relationship is not always true.

Finally, regarding the environmental dimension, there exists a positive relationship between $g d p$ and $p o l$, i.e. a marginal increase of $g d p$ produces an almost proportional increase of production of $\mathrm{CO}_{2}$. Among the other variables, as expected, it is relevant to mention the effect of urbanization on pol; in fact it is reasonable to believe that a high urbanization rate directly and indirectly affects the level of pollution through an increasing use of urban transport, high consumption of energy, electricity, and water, etc.

The coefficient of tels has a negative and significant sign, indicating that the information acts positively on the decrease of pollution. 
In conclusion, a bidirectional causality relationship exists between $g d p$ and life expectancy (le), while only a unidirectional one exists between $g d p$ and $l i$. Why does $l i$ not affect $g d p$ ? For developing countries, this factor is likely to be connected to the composition of the population characterized by low educated people employed in low productivity and traditional sectors (i.e. agriculture) which weakly affect the production of $g d p$. For developed countries, the unidirectional relationship may reflect the inability of countries to adequately employ their human capital with a high level of education and skills. Thus, in the long run, this could lead countries-with a high level of $g d p$ and $l i$ - to have a poor status, i.e. low $g d p$ and $l i$.

The positive and significant effect of $g d p$ on all social and environmental dimensions highlights that a good level of the economic dimension is a basic condition to achieve a good social-enviromental performance.

Actually, the estimates from the model give us relevant information on the average behaviour' across countries and over years. If we want to obtain more detailed information for each country at each time point, it would be useful to explore growth rates of economic (i.e. $g d p$ ) and social-environmental performance (i.e. $l e, l i$ and $p o l$ ). For this aim and in order to obtain a dynamic interpretation of our empirical results, we classify the countries in four groups:

1. High high $(\mathrm{HH})$ - countries with a rate of economic and social-environmental growth greater than the average value;

2. Low high (LH) - countries characterized by a growth rate of $g d p$ lower than the average value and a social or environmental performance (i.e. $l e, l i$ and $p o l$ ) greater than the average value;

3. High low (HL) — countries characterized by a growth rate of $g d p$ greater than the average value and a growth rate of social or environmental performance lower than the average value;

4. Low low (LL) - countries characterized by a growth rate of $g d p$ and social or environmental performance lower than the average value.

Table 2 Clustering of countries regarding the growth rate of $g d p, l i, l e, p o l$

\begin{tabular}{lcccc}
\hline & HH & LH & HL & LL \\
\hline gdp_li & & & & \\
$1985 / 1980$ & 17 & 16 & 11 & 20 \\
$1990 / 1985$ & 18 & 13 & 10 & 23 \\
$1995 / 1990$ & 12 & 17 & 16 & 19 \\
$1999 / 1995$ & 16 & 15 & 18 & 15 \\
gdp_le & & & 22 \\
$1985 / 1980$ & 11 & 14 & 13 & 20 \\
$1990 / 1985$ & 15 & 16 & 3 & 17 \\
$1995 / 1990$ & 25 & 19 & 7 & 7 \\
$1999 / 1995$ & 27 & 23 & & 26 \\
gdp_pol & & & 8 & 27 \\
$1985 / 1980$ & 20 & 10 & 14 & 28 \\
$1990 / 1985$ & 14 & 9 & 14 & 17 \\
$1995 / 1990$ & 14 & 8 & 12 & \\
$1999 / 1995$ & 22 & 13 & & \\
\hline
\end{tabular}


Table 2 shows the clustering of countries in the four groups according to growth rate of $g d p$, and $l e, l i$ and $p o l$, respectively. With respect to $g d p$ and $l e$, we note that the number of countries with an excellent performance (i.e. the group $\mathrm{HH}$ ) is increasing over time; it passes from 11 -at the first time point - to 27 at the last time point. In contrast, it is interesting to observe the number of countries with a bad performance (i.e. the group LL) decreases over time, declining from 22 to 7 . All this is the expression of the bidirectional causality relationship between $g d p$ and $l e$ highlighted by the simultaneous model, i.e. a high rate growth of $g d p$ supports the expectancy of a longer life, but, conversely, a lower rate growth of $l e$, i.e. the worst human health conditions, causes a country achieve lower growth and productivity in terms of $g d p$. Further, the countries included in the cluster HL decrease by of about $50 \%$ while the countries in the cluster LH increase over time.

Regarding the relationship between $g d p$ and $l i$, the clustering of the countries does not highlight a clear relationship between the two variables as was obtained from the SEM; the number of the clusters is almost stable over time for the $\mathrm{HH}$ and the $\mathrm{LH}$ ones, while the number of countries increases weakly in the HL cluster and decreases in the LL one.

With respect to $g d p$ and pol, only the cluster LL shows a significant change in the number of countries included in it, while we note the number of countries is almost stable in the clusters HH, HL and LH. In particular, we expected an increase of units in the HL cluster and, in contrast, a decrease of units in $\mathrm{HH}$ one, if countries with a high growth rate of $g d p$ had audited the environmental damage associated with economic growth.

In the light of these results, it would be interesting to trace the performance of each country in terms of growth rates for the period analysed, viz. 1980-1999. Tables 3 and 4 summarize the movements of countries from the start period (1980-1985) to the end period (1995-1999). In particular, Table 4 can be interpreted as a matrix of the transition/persistency status of countries. In fact, the main diagonal shows the persistency status of countries with respect to their beginning status (i.e. HH, LH, HL and LL); on the contrary the units above and below the main diagonal indicate the countries that move from a certain start status to a different end status.

Regarding the relationship between $g d p$ and $l e$ and $l i$, respectively, we can say that a unit follows a virtuous path if it moves directly from the cluster LL to $\mathrm{HH}$ or $\mathrm{LH}$; that means reaching a good economic performance matches social goals. Further, a country follows a virtuous path just as much if it moves from status HL and LH to HH. With respect to the first path (from $\mathrm{HL}$ to $\mathrm{HH}$ ), a territorial unit is able to manage its economic growth efficiently in order to increase its social development. Concerning the second path, i.e. from $\mathrm{LH}$ to $\mathrm{HH}$, a country exploits the good conditions of its people in terms of a high level of education and high health conditions to contribute to increase its economic growth.

In particular from Table 4, we note that the number of countries following a virtuous path is greater with respect to le (30) than to $l i(10)$. This result, already highlighted by the estimates of our model, confirms the bidirectional causal relationship between $g d p$ and $l e$. In other words, a high level of life expectancy has been an easier goal to reach for many countries, while a high level of education is a more difficult goal to achieve.

Relating to $g d p$ and $p o l$, a country proceeds along a virtuous path if it moves from the cluster HH to HL, but also from LL and LH to HL. In fact, it is important for both developed and developing countries to reach an economic growth process by monitoring the level of pollution through specific actions. From Table 4, we can count only 10 countries that have a virtuous status, i.e. the monitoring of environment has been a difficult problem to manage for the majority of countries. The polarization of countries in the clusters HH (20 countries) and LL (26 countries) indicates that a high level of economic 
Table 3 Movements of countries over time relating to cross-tabulated growth rates of $g d p$ and $l i, l e$ and $p o l$

\begin{tabular}{|c|c|c|c|c|c|c|c|c|c|c|c|c|}
\hline & \multicolumn{4}{|l|}{$g d p \_l i$} & \multicolumn{4}{|c|}{$g d p \_l e$} & \multicolumn{4}{|c|}{$g d p \_p o l$} \\
\hline & $\begin{array}{l}1985 / \\
1980\end{array}$ & $\begin{array}{l}1990 / \\
1985\end{array}$ & $\begin{array}{l}1995 / \\
1990\end{array}$ & $\begin{array}{l}1999 / \\
1995\end{array}$ & $\begin{array}{l}1985 / \\
1980\end{array}$ & $\begin{array}{l}1990 / \\
1985\end{array}$ & $\begin{array}{l}1995 / \\
1990\end{array}$ & $\begin{array}{l}1999 / \\
1995\end{array}$ & $\begin{array}{l}1985 / \\
1980\end{array}$ & $\begin{array}{l}1990 / \\
1985\end{array}$ & $\begin{array}{l}1995 / \\
1990\end{array}$ & $\begin{array}{l}1999 / \\
1995\end{array}$ \\
\hline Algeria & $\mathrm{HL}$ & LL & LH & $\mathrm{HH}$ & $\mathrm{HH}$ & LH & LH & $\mathrm{HH}$ & HL & LL & LL & $\mathrm{HL}$ \\
\hline Argentina & LL & LL & $\mathrm{HL}$ & HL & LL & LL & $\mathrm{HH}$ & $\mathrm{HH}$ & LL & LL & $\mathrm{HL}$ & $\mathrm{HH}$ \\
\hline Brazil & LL & LL & $\mathrm{HL}$ & LL & LL & LL & $\mathrm{HH}$ & $\mathrm{LH}$ & $\mathrm{LL}$ & LL & HL & $\mathrm{LH}$ \\
\hline Burkina Faso & HL & LL & LL & HL & $\mathrm{HL}$ & LL & LL & $\mathrm{HL}$ & $\mathrm{HL}$ & $\mathrm{LH}$ & LL & $\mathrm{HL}$ \\
\hline Burundi & $\mathrm{HL}$ & LL & LL & LL & $\mathrm{HL}$ & LL & LL & $\mathrm{LH}$ & $\mathrm{HH}$ & LL & $\mathrm{LL}$ & $\mathrm{LH}$ \\
\hline Cameroon & $\mathrm{HH}$ & $\mathrm{LH}$ & LH & $\mathrm{HH}$ & $\mathrm{HH}$ & LH & LL & $\mathrm{HL}$ & $\mathrm{HH}$ & LL & LH & $\mathrm{HL}$ \\
\hline $\begin{array}{l}\text { Central Afr. } \\
\text { Rep. }\end{array}$ & LL & LL & LL & LL & LL & LL & LL & LL & $\mathrm{LH}$ & LL & LL & LL \\
\hline Chile & LH & $\mathrm{HH}$ & $\mathrm{HL}$ & $\mathrm{HH}$ & LH & $\mathrm{HH}$ & $\mathrm{HH}$ & $\mathrm{HH}$ & LL & $\mathrm{HH}$ & $\mathrm{HL}$ & $\mathrm{HH}$ \\
\hline China & $\mathrm{HH}$ & $\mathrm{HH}$ & $\mathrm{HH}$ & $\mathrm{HH}$ & HL & HL & $\mathrm{HL}$ & $\mathrm{HH}$ & $\mathrm{HH}$ & $\mathrm{HL}$ & $\mathrm{HH}$ & $\mathrm{HH}$ \\
\hline Colombia & LH & $\mathrm{HL}$ & HL & LL & LL & $\mathrm{HL}$ & $\mathrm{HH}$ & $\mathrm{LH}$ & $\mathrm{LH}$ & HL & $\mathrm{HL}$ & LL \\
\hline $\begin{array}{l}\text { Congo, Dem. } \\
\text { Rep. }\end{array}$ & LL & LL & LL & LL & LL & LL & $\mathrm{LL}$ & LL & $\mathrm{LL}$ & LL & LL & LL \\
\hline Congo, Rep. & $\mathrm{HH}$ & LH & $\mathrm{LH}$ & LH & $\mathrm{HL}$ & $\mathrm{LL}$ & LL & LL & $\mathrm{HL}$ & $\mathrm{LH}$ & LL & LL \\
\hline Costa Rica & $\mathrm{LH}$ & $\mathrm{HL}$ & $\mathrm{HL}$ & $\mathrm{HH}$ & LL & $\mathrm{HL}$ & $\mathrm{HH}$ & $\mathrm{HH}$ & LL & $\mathrm{HL}$ & $\mathrm{HH}$ & $\mathrm{HL}$ \\
\hline $\begin{array}{l}\text { Cote } \\
\text { d'Ivoire }\end{array}$ & LL & LL & LL & $\mathrm{HL}$ & LL & LL & LL & $\mathrm{HL}$ & $\mathrm{LH}$ & LL & LL & $\mathrm{HH}$ \\
\hline Cyprus & $\mathrm{HH}$ & $\mathrm{HH}$ & $\mathrm{HH}$ & $\mathrm{HH}$ & $\mathrm{HL}$ & $\mathrm{HL}$ & $\mathrm{HL}$ & $\mathrm{HH}$ & $\mathrm{HL}$ & $\mathrm{HH}$ & $\mathrm{HL}$ & $\mathrm{HH}$ \\
\hline Ecuador & LH & LH & $\mathrm{LH}$ & LH & LL & LL & $\mathrm{LH}$ & $\mathrm{LH}$ & $\mathrm{LH}$ & LL & $\mathrm{LH}$ & LL \\
\hline $\begin{array}{l}\text { Egypt, Ar. } \\
\text { Rep. }\end{array}$ & $\mathrm{HL}$ & $\mathrm{HL}$ & LL & $\mathrm{HL}$ & $\mathrm{HH}$ & $\mathrm{HH}$ & $\mathrm{LH}$ & $\mathrm{HH}$ & $\mathrm{HH}$ & $\mathrm{HL}$ & LL & $\mathrm{HH}$ \\
\hline El Salvador & LL & LL & $\mathrm{HL}$ & LL & LH & $\mathrm{LH}$ & $\mathrm{HH}$ & $\mathrm{LH}$ & LL & LH & $\mathrm{HH}$ & $\mathrm{LH}$ \\
\hline Gambia, The & LL & LL & LL & $\mathrm{HL}$ & $\mathrm{LH}$ & LH & $\mathrm{LH}$ & $\mathrm{HH}$ & LL & LL & $\mathrm{LL}$ & $\mathrm{HL}$ \\
\hline Ghana & LL & LH & $\mathrm{LH}$ & $\mathrm{HH}$ & LH & LH & LH & $\mathrm{HL}$ & LH & LL & LL & $\mathrm{HL}$ \\
\hline Greece & $\mathrm{LH}$ & LH & $\mathrm{LH}$ & $\mathrm{HH}$ & $\mathrm{LL}$ & $\mathrm{LH}$ & LL & $\mathrm{HH}$ & $\mathrm{LH}$ & LL & $\mathrm{LL}$ & $\mathrm{HH}$ \\
\hline Guatemala & LL & LL & $\mathrm{HL}$ & LL & LL & $\mathrm{LH}$ & $\mathrm{HH}$ & $\mathrm{LH}$ & LL & $\mathrm{LH}$ & $\mathrm{HL}$ & LH \\
\hline Honduras & LL & LL & LL & LL & $\mathrm{LH}$ & $\mathrm{LH}$ & LH & $\mathrm{LH}$ & LL & $\mathrm{LH}$ & LH & $\mathrm{LH}$ \\
\hline Hungary & $\mathrm{HH}$ & $\mathrm{LH}$ & LL & HL & $\mathrm{HL}$ & LL & LL & $\mathrm{HH}$ & $\mathrm{HL}$ & LL & LL & $\mathrm{HH}$ \\
\hline India & $\mathrm{HL}$ & HL & $\mathrm{HL}$ & HL & $\mathrm{HH}$ & $\mathrm{HH}$ & $\mathrm{HH}$ & $\mathrm{HH}$ & $\mathrm{HH}$ & $\mathrm{HH}$ & $\mathrm{HH}$ & $\mathrm{HH}$ \\
\hline Indonesia & $\mathrm{HH}$ & $\mathrm{HH}$ & $\mathrm{HH}$ & $\mathrm{LH}$ & $\mathrm{HH}$ & $\mathrm{HH}$ & $\mathrm{HH}$ & $\mathrm{LH}$ & $\mathrm{HH}$ & $\mathrm{HH}$ & $\mathrm{HH}$ & $\mathrm{LL}$ \\
\hline $\begin{array}{l}\text { Iran, Islamic } \\
\text { Rep. }\end{array}$ & $\mathrm{HL}$ & LH & $\mathrm{HH}$ & $\mathrm{HH}$ & $\mathrm{HH}$ & LH & $\mathrm{HH}$ & $\mathrm{HH}$ & $\mathrm{HH}$ & LH & $\mathrm{HL}$ & $\mathrm{HH}$ \\
\hline Israel & $\mathrm{HH}$ & $\mathrm{HH}$ & $\mathrm{HH}$ & LH & HL & $\mathrm{HL}$ & $\mathrm{HH}$ & LH & $\mathrm{HH}$ & $\mathrm{HL}$ & $\mathrm{HH}$ & LL \\
\hline Italy & $\mathrm{HH}$ & $\mathrm{HH}$ & $\mathrm{LH}$ & LL & HL & $\mathrm{HL}$ & LL & $\mathrm{LH}$ & $\mathrm{HL}$ & HL & LL & LL \\
\hline Jamaica & LH & $\mathrm{HL}$ & LL & LL & $\mathrm{LL}$ & $\mathrm{HL}$ & $\mathrm{LH}$ & LH & LL & $\mathrm{HH}$ & $\mathrm{LL}$ & LH \\
\hline Japan & $\mathrm{HH}$ & $\mathrm{HH}$ & LH & LH & HL & $\mathrm{HL}$ & LL & $\mathrm{LH}$ & $\mathrm{HL}$ & $\mathrm{HL}$ & LL & LH \\
\hline Kenya & LH & $\mathrm{HH}$ & LH & LH & LH & $\mathrm{HL}$ & LL & LL & LL & $\mathrm{HH}$ & LL & LL \\
\hline Korea, Rep. & $\mathrm{HH}$ & $\mathrm{HH}$ & $\mathrm{HH}$ & $\mathrm{HH}$ & $\mathrm{HL}$ & $\mathrm{HH}$ & $\mathrm{HH}$ & $\mathrm{HH}$ & $\mathrm{HH}$ & $\mathrm{HH}$ & $\mathrm{HH}$ & $\mathrm{HH}$ \\
\hline Kuwait & LL & $\mathrm{HH}$ & $\mathrm{HL}$ & LL & LL & $\mathrm{HH}$ & $\mathrm{HH}$ & $\mathrm{LH}$ & LL & $\mathrm{HL}$ & $\mathrm{HH}$ & LL \\
\hline Madagascar & LL & LL & LL & LL & LL & LL & LH & LH & LL & LL & $\mathrm{LL}$ & LL \\
\hline Malawi & LL & $\mathrm{LL}$ & LL & $\mathrm{HL}$ & LL & $\mathrm{LL}$ & LL & $\mathrm{HL}$ & $\mathrm{LL}$ & $\mathrm{LL}$ & $\mathrm{LL}$ & $\mathrm{HL}$ \\
\hline Malaysia & $\mathrm{HH}$ & $\mathrm{HH}$ & $\mathrm{HH}$ & LH & HL & $\mathrm{HL}$ & $\mathrm{HH}$ & LH & $\mathrm{HH}$ & $\mathrm{HH}$ & $\mathrm{HH}$ & LH \\
\hline
\end{tabular}


Table 3 continued

\begin{tabular}{|c|c|c|c|c|c|c|c|c|c|c|c|c|}
\hline & \multicolumn{4}{|l|}{$g d p \_l i$} & \multicolumn{4}{|l|}{ gdp_le } & \multicolumn{4}{|c|}{ gdp_pol } \\
\hline & $\begin{array}{l}1985 / \\
1980\end{array}$ & $\begin{array}{l}1990 / \\
1985\end{array}$ & $\begin{array}{l}1995 / \\
1990\end{array}$ & $\begin{array}{l}1999 / \\
1995\end{array}$ & $\begin{array}{l}1985 / \\
1980\end{array}$ & $\begin{array}{l}1990 / \\
1985\end{array}$ & $\begin{array}{l}1995 / \\
1990\end{array}$ & $\begin{array}{l}1999 / \\
1995\end{array}$ & $\begin{array}{l}1985 / \\
1980\end{array}$ & $\begin{array}{l}1990 / \\
1985\end{array}$ & $\begin{array}{l}1995 / \\
1990\end{array}$ & $\begin{array}{l}1999 / \\
1995\end{array}$ \\
\hline Mali & LL & LL & LL & HL & LH & LL & LL & HL & LL & LL & LL & HL \\
\hline Malta & $\mathrm{HH}$ & $\mathrm{HH}$ & $\mathrm{HH}$ & $\mathrm{HH}$ & HL & $\mathrm{HL}$ & $\mathrm{HH}$ & $\mathrm{HH}$ & $\mathrm{HH}$ & $\mathrm{HH}$ & $\mathrm{HL}$ & $\mathrm{HH}$ \\
\hline Mauritius & $\mathrm{HL}$ & $\mathrm{HL}$ & HL & HL & HL & $\mathrm{HH}$ & $\mathrm{HH}$ & $\mathrm{HH}$ & $\mathrm{HH}$ & $\mathrm{HH}$ & $\mathrm{HH}$ & $\mathrm{HH}$ \\
\hline Mexico & LH & LH & LH & HL & LL & LL & LH & $\mathrm{HH}$ & LL & LL & LL & $\mathrm{HH}$ \\
\hline Morocco & HL & HL & LL & HL & $\mathrm{HH}$ & $\mathrm{HH}$ & LH & $\mathrm{HH}$ & $\mathrm{HH}$ & HL & LH & $\mathrm{HH}$ \\
\hline Nepal & HL & HL & $\mathrm{HL}$ & HL & $\mathrm{HH}$ & $\mathrm{HH}$ & $\mathrm{HH}$ & $\mathrm{HH}$ & $\mathrm{HH}$ & HL & $\mathrm{HH}$ & $\mathrm{HH}$ \\
\hline Nicaragua & LL & LL & LL & HL & LH & LH & LH & $\mathrm{HH}$ & LL & LH & LL & $\mathrm{HH}$ \\
\hline Oman & $\mathrm{HH}$ & LH & $\mathrm{LH}$ & LH & $\mathrm{HH}$ & LH & LH & LH & $\mathrm{HH}$ & LL & LL & LL \\
\hline Pakistan & $\mathrm{HL}$ & $\mathrm{HL}$ & $\mathrm{HL}$ & LL & $\mathrm{HH}$ & $\mathrm{HH}$ & $\mathrm{HH}$ & LH & $\mathrm{HH}$ & $\mathrm{HH}$ & $\mathrm{HL}$ & LH \\
\hline Paraguay & LH & LH & LH & LH & LL & LL & LH & LH & LL & LH & LH & LL \\
\hline Peru & LH & LH & $\mathrm{HH}$ & LH & LH & LH & $\mathrm{HH}$ & LH & LL & LL & HL & LH \\
\hline Philippines & LH & $\mathrm{HH}$ & LH & LH & LL & $\mathrm{HH}$ & LH & LH & LL & $\mathrm{HH}$ & LH & LH \\
\hline Rwanda & LL & LL & LL & $\mathrm{HH}$ & $\mathrm{LH}$ & LL & LL & $\mathrm{HH}$ & LH & LL & LL & HL \\
\hline Senegal & LL & LL & LL & $\mathrm{HL}$ & LH & LH & LH & $\mathrm{HH}$ & LL & LL & LL & $\mathrm{HL}$ \\
\hline Singapore & $\mathrm{HH}$ & $\mathrm{HH}$ & $\mathrm{HH}$ & $\mathrm{HH}$ & $\mathrm{HL}$ & $\mathrm{HL}$ & $\mathrm{HH}$ & $\mathrm{HH}$ & $\mathrm{HL}$ & $\mathrm{HH}$ & $\mathrm{HH}$ & $\mathrm{HH}$ \\
\hline South Africa & LL & LL & LL & LL & LH & LH & LL & LL & LH & LL & LL & LL \\
\hline Sri Lanka & HL & HL & HL & HL & HL & HL & $\mathrm{HH}$ & $\mathrm{HH}$ & $\mathrm{HH}$ & HL & $\mathrm{HH}$ & $\mathrm{HH}$ \\
\hline Swaziland & LH & $\mathrm{HH}$ & LH & LL & LH & $\mathrm{HH}$ & LH & LL & LL & HL & LL & LL \\
\hline $\begin{array}{c}\text { Syrian ArHL } \\
\text { Republic }\end{array}$ & LL & LL & HL & HL & LH & LH & $\mathrm{HH}$ & $\mathrm{HH}$ & LH & LL & HL & HL \\
\hline Thailand & $\mathrm{HH}$ & $\mathrm{HH}$ & $\mathrm{HH}$ & LH & $\mathrm{HL}$ & $\mathrm{HH}$ & HL & LH & $\mathrm{HH}$ & $\mathrm{HH}$ & $\mathrm{HH}$ & LH \\
\hline $\begin{array}{c}\text { Trinidad and } \\
\text { ToLHgo }\end{array}$ & LH & LL & LL & HL & LL & LL & LH & $\mathrm{HH}$ & LH & LL & LH & $\mathrm{HH}$ \\
\hline Tunisia & $\mathrm{HH}$ & LL & $\mathrm{HL}$ & $\mathrm{HH}$ & $\mathrm{HH}$ & LH & $\mathrm{HH}$ & $\mathrm{HH}$ & $\mathrm{HH}$ & LL & $\mathrm{HL}$ & $\mathrm{HH}$ \\
\hline Turkey & $\mathrm{HH}$ & $\mathrm{HH}$ & $\mathrm{HH}$ & LH & HL & $\mathrm{HH}$ & $\mathrm{HH}$ & LH & $\mathrm{HH}$ & HL & HL & LH \\
\hline Uruguay & LH & $\mathrm{HH}$ & $\mathrm{HH}$ & $\mathrm{HH}$ & LL & $\mathrm{HL}$ & $\mathrm{HH}$ & $\mathrm{HH}$ & LL & $\mathrm{HL}$ & HL & $\mathrm{HH}$ \\
\hline $\begin{array}{l}\text { Venezuela, } \\
\text { RB }\end{array}$ & LH & LH & LH & LH & LL & LL & LH & LH & LL & LL & LH & LL \\
\hline Zambia & LL & LL & LH & LH & LL & LL & LL & LL & LL & LL & LL & LL \\
\hline Zimbawe & LH & LH & LH & $\mathrm{HH}$ & LL & LL & LL & $\mathrm{HL}$ & LL & LH & LL & $\mathrm{HL}$ \\
\hline
\end{tabular}

growth implies a social cost in terms of environmental damage; on the other hand, a low economic growth is not likely to imply environmental damage.

\section{Conclusion}

We have proposed a rational scheme in which future research on economic, social and environmental performance of countries can be positioned and nested. By using a structural SEM, we have estimated the intensity of causal relationships among economic, social and environmental variables, and we have controlled for endogeneity.

Obviously, our scheme is not exhaustive and additional aspects could be considered as well (e.g. ones related to income inequality, quality of diet, time and leisure, etc.). 
Table 4 Persistency/transition matrix from 1980 to 1999

\begin{tabular}{ccccc}
\hline & HH & LH & HL & LL \\
\hline gdp_li & & & & \\
HH & 7 & 8 & 1 & 1 \\
LH & 5 & 6 & 2 & 3 \\
HL & 2 & 0 & 7 & 2 \\
LL & 2 & 1 & 8 & 9 \\
gdp_le & & & & \\
HH & 7 & 3 & 1 & 3 \\
LH & 6 & 3 & 2 & 1 \\
HL & 8 & 7 & 1 & 3 \\
LL & 6 & 10 & & 3 \\
gdp_pol & & 5 & 3 & 4 \\
HH & 11 & 0 & 2 & 2 \\
LH & 3 & 1 & 6 & 8 \\
HL & 3 & 7 & & \\
LL & 5 & & & \\
\hline
\end{tabular}

Nevertheless, at this moment, our analysis is a new attempt to integrate the economic, social, and environmental aspects of countries' performances simultaneously.

By using a SEM, our attempt represents a rather novel methodological approach to analyse a multidimensional phenomenon on such as country well-being, traditionally treated by means of statistical multivariate methods or composite indicators.

The estimations show that $g d p$ is a basic condition to obtain a good social performance: a high level of $g d p$ permits inhabitants to have a longer life expectancy and to achieve a higher level of education. But the other side of the coin is that high levels of $g d p$ increase the level of pollution. In particular for developing countries, this insight implies that policy makers have to pay attention to controlling and monitoring the negative effects of economic growth on the environment.

Furthermore, the empirical analysis reveals a strong bidirectional relationship between $g d p$ (the economic performance indicator) and one of the social performance indicators, life expectancy.

In contrast, a unidirectional relationship between $g d p$ and $l i$ has been found. This result could be related to a slower response of $g d p$ to human capital changes, viz. a higher quality level of human capital does not turn immediately into a higher level of $g d p$.

As our empirical analysis has mainly concerned developing countries, we may hypothesize that the countries analysed have not reached the minimum threshold that permits them to move from an economy characterized by a low productivity level to a country characterized by a high productivity level .

Finally, the results obtained show that life expectancy does not serve to distinguish between the countries, while the literacy rate and $\mathrm{CO}_{2}$ emissions are better able to capture the differences between countries in terms of their social and environmental dimensions. In particular, with respect to the literacy rate a similar result has been obtained from McGillivary (2005).

From a policy point of view, the above result indicates that, for most of the countries that were examined, more efforts should have been made to improve their social and environmental performance, viz. in order to increase the level of the literacy rate and to 
control the $\mathrm{CO}_{2}$ emissions. More specifically, in agreement with several strands of the literature, the policy response to spatial inequality or disparity could be based on:

- Supply-side policy of a Keynesian nature, with a pronounced interest in public spending in less privileged regions or nations;

- Growth pole strategies, with a clear emphasis on a concentrated growth impulse in a few designated regions;

- Infrastructure policy, with the aim of creating the necessary physical conditions (e.g. improvement of accessibility) in order to enhance the competitive capabilities of regions or nations;

- Self-organizing policy, where actors are encouraged to get their acts together on the basis of their own indigenous strength with a limited role of governments;

- Suprastructure policy, in which regions are provided with favourable R\&D conditions, educational facilities, knowledge centres, and the like, in order to create the conditions for self-sustained development.

In summary, our paper has tried to investigate and explore country performance regarding all aspects, economic and non-economic, simultaneously. Further, as the results obtained from the model give us insights into the average behaviour of countries over time, a matrix of persistency and transition status has been made. This analysis confirms the empirical results derived from the model, and highlights the inability of most countries, over time, either to turn the higher educational skills of their population into greater $g d p$ or to improve the level of education in order to move from a low productivity economy to a higher productivity one.

Acknowledgments We are specially grateful to Raymond Florax to have discussed with us the research idea and to have encouraged us to use a simultaneous equations model. Moreover, we would like to thank Cristina Bernini and Piet Rietveld for the useful suggestions on the econometric estimates.

Open Access This article is distributed under the terms of the Creative Commons Attribution Noncommercial License which permits any noncommercial use, distribution, and reproduction in any medium, provided the original author(s) and source are credited.

\section{References}

Barro, R., \& Sala-i-Martin, X. (1992). Convergence. Journal of Political Economy, 100(2), 223-251.

Bohringer, C., \& Jochem, P. E. P. (2007). Measuring the immeasurable-a survey of sustainability indices. Ecological Economics, 63, 1-8. doi:10.1016/j.ecolecon.2007.03.008.

Common, M., \& Stagl, S. (2005). Ecological economics, an introduction. Cambridge: Cambridge University Press.

Cracolici, M. F., Cuffaro, M., \& Nijkamp, P. (2009). Tourism sustainability and economic efficiency: A statistical analysis of Italian provinces. In L. Fusco Girard and P. Nijkamp (Eds.), Cultural tourism and sustainable local development. Aldershot: Ashgate.

Cuffaro, M., Cracolici, M. F., \& Nijkamp, P. (2008). Measuring the performance of Italian regions on social and economic dimensions. Italian Journal of Regional Science, 7, $27-47$.

Daly, H. E., \& Cobb, J. B. (1989). For the common good: Redirecting the economy towards community, the environment and a sustainable future. Boston: Beacon Press.

Dasgupta, P. (1990). Well-being and the extent of its realization in poor countries. The Economic Journal, 100, 1-32. doi:10.2307/2234181.

Dasgupta, S., Hamilton, K., Pandey, K. D., \& Wheeler, D. (2006). Environment during growth: Accounting for governance and vulnerability. World Development, 34, 1597-1611. doi:10.1016/j.worlddev.2005. 12.008.

Dasgupta, P., \& Weale, M. (1992). On measuring the quality of life. World Development, 20(1), 119-131. doi:10.1016/0305-750X(92)90141-H. 
Davidson, E. A. (2000). You can't eat GNP: Economics as if ecology mattered. Cambridge, MA: Perseus.

Desai, M. (1991). Human development: Concepts and measurement. European Economic Review, 35, 350357. doi:10.1016/0014-2921(91)90136-7.

Distaso, A. (2007). Well-being and/or quality of life in EU countries through a multidimensional index of sustainability. Ecological Economics, 64, 163-180. doi:10.1016/j.ecolecon.2007.02.025.

Färe, R., Grosskopf, S., \& Roos, P. (1994). Productivity and quality changes in Swedish pharmacies, Discussion Paper, Southern Illinois University, Carbondale. IL.

Giles, D. E. A., \& Feng, H. (2005). Output and well-being industrialized nations in the second half of the 20th century: Testing for convergence using fuzzy clustering analysis. Structural Change and Economic Dynamics, 16, 285-308. doi:10.1016/j.strueco.2004.08.001.

Hobijn, B., \& Franses, P. H. (2001). Are living standards converging? Structural Change and Economic Dynamics, 12, 171-200. doi:10.1016/S0954-349X(00)00034-5.

Hsiao, C. (2003). Analysis of panel data. Cambridge: Cambridge University Press.

Khan, H. (1991). Measurement and determinants of socioeconomic development: A critical conspectus. Social Indicators Research, 24, 153-175. doi:10.1007/BF00300358.

Kuznets, S. (1973). Modern economic growth: Findings and reflections. The American Economic Review, 63(3), 247-258.

Marchante, A. J., \& Ortega, B. (2006). Quality of life and economic convergence across Spanish regions, 1980-2001. Regional Studies, 40(5), 471-483. doi:10.1080/00343400600757460.

Mazumdar, K. (2000). Causal flow between well-being and per capita real gross domestic product. Social Indicators Research, 50, 297-313. doi:10.1023/A:1007061703600.

McGillivary, M. (1991). The human development index: Yet an other redundant composite development indicator? World Development, 19(10), 1461-1468. doi:10.1016/0305-750X(91)90088-Y.

McGillivary, M. (2005). Measuring non-economic well-being achievement. Review of Income and Wealth, 51, 337-364. doi:10.1111/j.1475-4991.2005.00157.x.

McGillivary, M., \& Shorrocks, A. (2005). Inequality and multidimensional well-being. Review of Income and Wealth, 51, 193-200. doi:10.1111/j.1475-4991.2005.00151.x.

Neumayer, E. (1999). The ISEW-not an index of sustainable economic welfare. Social Indicators Research, 48, 77-101. doi:10.1023/A:1006914023227.

Neumayer, E. (2000). On the methodology of ISEW, GPI and related measures: Some constructive suggestions and some doubt on the threshold hypothesis. Ecological Economics, 34, 347-361. doi: 10.1016/S0921-8009(00)00192-0.

Neumayer, E. (2003). Beyond income: Convergence in living standards, big time. Structural Change and Economic Dynamics, 14, 275-296. doi:10.1016/S0954-349X(02)00047-4.

Noorbakhsh, F. (1998). A modified human development index. World Development, 26, 517-528. doi: 10.1016/S0305-750X(97)10063-8.

Osberg, L., \& Sharpe, A. (2005). How should we measure the 'economic' aspects of well-being? Review of Income and Wealth, 51(2), 311-336. doi:10.1111/j.1475-4991.2005.00156.x.

Pulselli, F. M., Ciampalini, F., Tiezzi, E., \& Zappia, C. (2006). The index of sustainable economic welfare (ISEW) for a local authority: A case study in Italy. Ecological Economics, 60, 271-281.

Ram, R., \& Schultz, T. W. (1979). Life span, health, savings, and productivity. Economic Development and Cultural Change, 27, 399-421. doi:10.1086/451107.

Ranis, G., Stewart, F., \& Ramirez, A. (2000). Economic growth and human development. World Development, 28, 197-219. doi:10.1016/S0305-750X(99)00131-X.

Sagar, A. D., \& Najam, A. (1998). The human development index: A critical review. Ecological Economics, 25(33), 249-264. doi:10.1016/S0921-8009(97)00168-7.

Sen, A. (1984). Resources, values and development. Oxford: Blackwell.

Sen, A. (1985). Commodities and capabilities. Amsterdam: North Holland Press.

Sen, A. (1987). Standard of living. New York: Cambridge University Press.

Shephard, R., \& Färe, R. (1974). The law of diminishing returns. Zeitschrift fur Nationalokonomie, 34, 69-90. doi:10.1007/BF01289147.

Solow, R. A. (1956). Contribution to the theory of economic growth. The Quarterly Journal of Economics, 70, 65-94. doi:10.2307/1884513.

UNDP. (1990). Human development report. New York: Oxford University Press.

UNDP. (1991). Human development report. New York: Oxford University Press.

UNDP. (1997). Human development report. New York: Oxford University Press.

Welsch, H. (2007). Environmental welfare analysis: A life satisfaction approach. Ecological Economics, 62, 544-551. doi:10.1016/j.ecolecon.2006.07.017.

World Bank. (2001). World development indicators. Washington: World Bank.

Zuvekas, C., Jr. (1979). Economic development. New York: St Martin's Press. 